\title{
Cellular and molecular etiology of hepatocyte injury in a murine model of environmentally induced liver abnormality
}

\author{
M.A. Al-Griw ${ }^{1, *}$, R.O. Alghazeer ${ }^{2}$, S.A. Al-Azreg ${ }^{3}$ and E.M. Bennour ${ }^{4}$ \\ ${ }^{1}$ Division of Developmental Biology, Zoology Department, Faculty of Science, University of Tripoli, Tripoli, Libya \\ ${ }^{2}$ Chemistry Department, Faculty of Science, University of Tripoli, Tripoli, Libya \\ ${ }^{3}$ Department of Pathology and Clinical Pathology, Faculty of Veterinary Medicine, University of Tripoli, \\ Tripoli, Libya \\ ${ }^{4}$ Department of Internal Medicine, Faculty of Veterinary Medicine, University of Tripoli, Tripoli, Libya
}

\begin{abstract}
Exposures to a wide variety of environmental substances are negatively associated with many biological cell systems both in humans and rodents. Trichloroethane (TCE), a ubiquitous environmental toxicant, is used in large quantities as a dissolvent, metal degreaser, chemical intermediate, and component of consumer products. This increases the likelihood of human exposure to these compounds through dermal, inhalation and oral routes. The present in vivo study was aimed to investigate the possible cellular and molecular etiology of liver abnormality induced by early exposure to TCE using a murine model. The results showed a significant increase in liver weight. Histopathological examination revealed a TCE-induced hepatotoxicity which appeared as heavily congested central vein and blood sinusoids as well as leukocytic infiltration. Mitotic figures and apoptotic changes such as chromatin condensation and nuclear fragments were also identified. Cell death analysis demonstrates hepatocellular apoptosis was evident in the treated mice compared to control. TCE was also found to induce oxidative stress as indicated by an increase in the levels of lipid peroxidation, an oxidative stress marker. There was also a significant decrease in the DNA content of the hepatocytes of the treated groups compared to control. Agarose gel electrophoresis also provided further biochemical evidence of apoptosis by showing internucleosomal DNA fragmentation in the liver cells, indicating oxidative stress as the cause of DNA damage. These results suggest the need for a complete risk assessment of any new chemical prior to its arrival into the consumer market.
\end{abstract}

Keywords: Apoptosis, DNA damage, Environmental toxicant, Liver, Oxidative stress.

\section{Introduction}

The extensive use of chemicals has been recently criticized due to their persistence in the environment and their accumulation in the tissues of organisms. One of the most concerned issues in the modern society is evaluating the toxicity of environmental (pollutant) chemicals, such as cadmium, mercury, bisphenol A (BPA), dioxin and trichloroethane (TCE). Some of these toxicants show immediate effect whereas others can result in subtle alterations that are delayed in their expression (Wang et al., 2013). TCE is considered as ubiquitous environmental toxicant and it is a volatile organic solvent that has been used in large quantities as an industrial dissolvent, a metal degreaser, a chemical intermediate, and as a component of consumer products (Warren et al., 1998; Wang et al., 2013). TCE has been originally produced as a safer alternative to other chlorinated solvents; as its acute and chronic toxicities are relatively low (EPA, 2007). However, the exposure to high concentrations of TCE could result in toxic effects especially to those who are subjected to TCE either in the workplace or to those who recreationally abuse the solvent (Warren et al., 1998; ATSDR, 2006).
In humans, epidemiological studies showed that acute exposure have produced an impaired performance in the tests of manual dexterity, eye-hand coordination, perceptual speed and reaction time (Mackay et al., 1987; Warren et al., 1998). While severe exposures to TCE have resulted in sensitization of the heart to epinephrine-induced arrhythmias and mild hepatorenal effects (ATSDR, 2006).

Liver function can be affected through several cellular and molecular mechanisms. Numerous studies have suggested oxidative alterations in hepatocytes such as mitochondrial dysfunction, membrane injury and denaturation of DNA and other cell components (Kurose et al., 1997). Excessive production of reactive oxygen species (ROS), such as the superoxide anion $\mathrm{O}_{2}^{-}$and hydroxyl radicals $\left(\mathrm{HO}^{-}\right)$can lead to altered enzyme activity, decreased DNA repair, impaired utilization of oxygen, glutathione depletion, and lipid peroxidation. Some of these alterations induced by oxidative stress have been recognized to be characteristic features of necrosis (Gujral et al., 2001, 2002). ROS has been involved in the pathogenesis of diseases and a variety of ROS-mediated modifications of proteins have been

*Corresponding Author: Dr. Mohamed A. Al-Griw. Division of Developmental Biology, Zoology Department, Faculty of Science, University of Tripoli, P.O. Box 13160, Tripoli, Libya. E-mail: m.algriw@uot.edu.ly 
reported in various diseases (Khan et al., 2001; Morgan et al., 2005; Oates, 2010; Wang et al., 2013). Proteins perform crucial functions within living cells, but even a relatively minor structural modification of proteins often leads to a marked change (generally lowering) in their functions (Orengo et al., 1999). Increasing evidence suggests that ROS-modified proteins such as protein carbonyls and lipid peroxidation-derived aldehydes [LPDAs, including malondialdehyde (MDA) and 4-hydroxynonenal (HNE)]-protein adducts may elicit an autoimmune response and contribute to disease pathogenesis (Ben Mansour et al., 2010). Indeed, higher levels of MDA-/HNE-modified proteins and protein carbonyls have been seen in autoimmune disease patients (Ben Mansour et al., 2010; Wang et al., 2010), illustrating a role for these oxidative modified proteins in autoimmune diseases. Oxidative stress can affect cell integrity only when antioxidant mechanisms are no longer able to cope with free radical generation. The cell death could be either through apoptosis or necrosis. The apoptosis is a permanent cell death where nucleus undergoes fragmentation, whereas the necrosis results from reversible cellular changes, as under favorable condition necrotic cells become a normal cell (Chattopadhyay and Wahi, 2009). During injury, cells die by a combination of several mechanisms including intracellular oxidant stress, exposure to external cytotoxic mediators, and prolonged ischemia. Cell death of hepatocytes following liver injury is characterized by swelling of cells and their organelles, release of cell contents, eosinophilia, karyolysis, and induction of inflammation (Chattopadhyay et al., 2007). These morphological features are characteristic of oncotic necrosis. It was postulated that most liver cells actually die by apoptosis (Chattopadhyay et al., 2007; Chattopadhyay and Wahi, 2009), which is morphologically characterized by cell shrinkage, formation of apoptotic bodies with intact cell organelles and the absence of inflammation (Chattopadhyay and Wahi, 2009). It has been documented that $50-80 \%$ of liver endothelial cells and hepatocytes die through apoptosis during the first three to six hours following injury (Gujral et al., 2001). Immediate cell contents release and inflammation are not consistent with apoptosis as the only mode of cell death and interventions such as overexpression of BCL-2 can prevent both apoptotic and necrotic cell injury (Gujral et al., 2001, 2002). Previously, many laboratories reported evidence for apoptotic cell death after liver injury (Gujral et al., 2002). According to these studies, $50-70 \%$ of endothelial cells and $40-60 \%$ of hepatocytes undergo apoptosis during ischaemic reperfusion (Gujral et al., 2002). A high percentage of apoptotic hepatocytes were also identified in human liver allografts (Gujral et al., 2001, 2002). Although there is morphological evidence of apoptosis for individual cells, the quantitation of apoptosis in the tissue was mainly based on the TUNEL assay (Gujral et al., 2001, 2002). In addition to these parameters, DNA laddering and moderate caspase-3 activation were also reported (Gujral et al., 2001, 2002).

As little data is available regarding the molecular and cellular etiology of TCE-mediated liver abnormality, therefore, the aim of this study was to investigate, through an in vivo murine model, the possible contribution of oxidative stress, DNA damage and apoptosis in TCE-mediated hepatotoxicity.

\section{Animals and housing}

\section{Materials and Methods}

All efforts were made to fulfill the ethical experimentation standards such as minimizing the pain during animal handling and experiments as well as reducing the number of animals used. A total of twenty four Swiss albino mice, with an age range of three to five weeks and weight range of 21-24 g, were used in this study. They were bred in the animal house of the Zoology Department (Faculty of Science, University of Tripoli, Tripoli, Libya) and housed under natural conditions of light (12 hour cycle), temperature $\left(24 \pm 2^{\circ} \mathrm{C}\right)$ and $55 \pm 5 \%$ relative humidity. Food and drinking water were available ad libitum.

\section{Experimental design}

Animals were divided into four groups of six mice each. These groups were: Two TCE-treated groups, sham control group and vehicle control group. Various concentrations of TCE (Baxter International) were dissolved in corn oil and administered to mice intraperitoneally with repeated doses (100 or $400 \mu \mathrm{g} / \mathrm{kg}$ BW TCE twice weekly for three weeks). The doses were calculated and delivered in 80-100 $\mu \mathrm{l}$ of corn oil based on their body weight (Melani et al., 2003; Wang et al., 2013). TCE doses were selected as they considered safe by Environmental Protection Agency (EPA) (Lane et al., 1982). Mice serving as vehicle control received just the corn oil. However, the sham control group neither receive the toxicant (TCE) nor the vehicle (corn oil). The exposure window was selected because this is the critical development window in the mouse (Wang et al., 2014).

\section{Clinical assessment}

All the animals were regularly observed for the signs of toxicity and survival rate was recorded during the entire study. Two independent observers confirmed the cause of death to exclude TCE-nonrelated mortality. The body weight of each animal was recorded at the initiation of study and once a week during the study, as well as prior to sacrifice.

\section{Tissue processing and histopathology}

For necropsy, mice were deeply anesthetized then euthanized. The livers were dissected immediately and washed with normal saline. Then, saline was soaked on blotting paper and liver weight was recorded for 
each individual animal and the liver was immediately preserved in $10 \%$ formalin. For histological examination, slides were prepared as described by Bancroft and Cook (1984). The liver architecture was observed and imaged using low- and high-power objectives under a light microscope (Leica, Germany).

\section{Scoring of cell death}

To assess cell death, images of H\&E-stained liver sections were examined by using ImageJ software (version 1.45) and a manual count was performed. Cell numbers were expressed as a percentage of the number present for each treatment group and an overall percentage obtained by averaging the data for all cells within a treatment group. Apoptotic cells were identified by morphological criteria such as cell shrinkage, chromatin condensation and margination, and apoptotic bodies (Gujral et al., 2001), while hepatocytes undergoing necrosis were identified using the criteria as increased eosinophilia, cell swelling and lysis, loss of architecture, karyolysis and karyorrhexis. The percent of apoptosis was estimated by evaluating the number of microscopic fields with apoptosis compared to the entire histologic section. The scoring scale was set from 0 to 5 , with the following criteria: (0): No necrosis; (1): Mild; (2): Mild to moderate; (3): Moderate; (4): Moderate to severe; and (5): Severe. For each liver section, the eight scores were averaged, and this average was considered as a replicate. All histopathology work was done in randomly selected animals by two independent examiners.

\section{DNA isolation and electrophoresis}

For genomic analysis, hepatic tissues of control and TCE-treated mice were kept deeply frozen. DNA was isolated using a QIAamp DNA MiniKit (Qiagen). In brief, up to $25 \mathrm{mg}$ of tissue samples were ground into small pieces and homogenized in DNA lysis buffer and proteinase $\mathrm{K}(2 \mathrm{mg} / \mathrm{mL})$ and incubated in the same buffer overnight at $56^{\circ} \mathrm{C}$. Samples were treated with RNase A (20 mg/mL), purified on spin column and eluted with Tris/EDTA buffer. The extracted DNA was measured by UV spectrophotometry (BioPhotometer, eppendorf), with an absorbance of A260/A280 nm ratios at $\mathrm{pH}$ 8.0. To determine the integrity of the extracted DNA, three micrograms of each DNA extract were fractionated by electrophoresis on $1.5 \%$ agarose gel. The gel was stained with GelRed ${ }^{\mathrm{TM}}$ (Sigma) and the DNA bands were visualized under UV light source.

\section{Lipid peroxidation (LPO) assay}

The thiobarbituric acid reactive substances (TBARS) assay, which measures MDA (an end product of lipid peroxidation) concentration, has been used as a measure of oxidative stress (Dalle-Donne et al., 2006). Briefly, $0.2 \mathrm{ml}$ of liver homogenate $(10 \% \mathrm{~W} / \mathrm{V}$ in Phosphate buffered saline) was added to $100 \mu \mathrm{BHA}$ to prevent further oxidation and $500 \mu \mathrm{l}$ of $25 \% \mathrm{HCl}$ and $500 \mu \mathrm{l} 1 \%$ TBA. The mixture was vortexed for
$20 \mathrm{sec}$ and incubated in a water bath at $90{ }^{\circ} \mathrm{C}$ for $1 \mathrm{~h}$ and cooled down to $20^{\circ} \mathrm{C}$. The mixture was measured for absorbance at $532 \mathrm{~nm}$ using a spectrophotometer (Jenway UV-6305, Essex, England). The calibration curve was obtained using different concentrations of 1 , 1, 3, 3-tetramethoxypropane as standard to determine the concentration of TBA-MDA adducts in samples as $\mathrm{nmol} / \mathrm{ml}$ (Utley et al., 1967).

\section{Statistics}

Statistical significance was determined using analysis of variance or t-test, as appropriate (SPSS, version 20). Data are presented as means \pm standard error of the mean (SEM).

\section{Results}

Impact of TCE on animal survival

The TCE treatment did not affect the survival/mortality rate of the animals as compared to control during the experiment.

\section{TCE exposure increases liver weight but not body weight}

The body and liver weights in the different groups have been monitored in order to investigate the impact of TCE on such parameters. The results showed that TCE insult had no significant effect on the overall body weight (Table 1). There was a significant increase in the liver weight of $400 \mu \mathrm{g} / \mathrm{kg}$ TCE-treated group compared to control $(P=0.01)$. The vehicle had no significant effect on the body and liver weights when applied under normoxic conditions (Table 1). No significant changes were observed in the liver weight of $100 \mu \mathrm{g} / \mathrm{kg}$ TCEtreated groups (Table 1) indicating that TCE at the dose of $100 \mu \mathrm{g} / \mathrm{kg}$ bw is a No Observed Adverse Effective Level (NOAEL) for mice in this study.

\section{TCE induces vascular and degenerative changes in hepatic architecture}

At necropsy, no gross pathological changes have been noticed on the livers of control and TCE-treated mice. The histopathological examination of liver tissues of sham control group exhibited normal architecture of hepatocytes, blood sinusoids, and portal areas including hepatic portal vein, hepatic artery, and bile ducts (Fig. 1a). The liver sections of TCE-treated mice revealed different histopathological changes represented by mild congestion of hepatic blood vessels, perivascular aggregation of lymphocytes in

Table 1. The impact of TCE on body and liver weights.

\begin{tabular}{lcc}
\hline Groups & Bodyweight $(g)$ & Liver weight $(g)$ \\
\hline Sham & $27.91 \pm 0.71$ & $1.26 \pm 0.23$ \\
Vehicle & $28.56 \pm 1.19$ & $1.27 \pm 0.13$ \\
$100 \mu \mathrm{g} / \mathrm{kg} \mathrm{TCE}$ & $28.25 \pm 0.67$ & $1.43 \pm 0.04$ \\
$400 \mu \mathrm{g} / \mathrm{kg} \mathrm{TCE}$ & $31.08 \pm 0.86$ & $1.89 \pm 0.21^{*}$ \\
\hline
\end{tabular}

Data are represented as mean \pm SEM ( $\mathrm{n}=6-8$ per group)

*Significantly different from control $(P \leq 0.05)$. 
portal area and hydropic degeneration of hepatocytes in centrolobular zone. Furthermore, sections exhibited some hepatocytes with mitotic figures and activated Kuffer cells. In $100 \mu \mathrm{g} / \mathrm{kg}$ TCE-treated mice, the histological examination of hepatic tissues showed a mild vascular congestion and dilation, perivascular cloudy swelling and hydropic degeneration, mild biliary proliferation, and interstitial and periportal aggregation of lymphocytes (Fig. 1b). The hepatic tissues of mice received $400 \mu \mathrm{g} / \mathrm{kg}$ TCE treatment showed a vascular congestion and cellular degeneration evidenced by cloudy swelling of hepatocytes with proliferation of bile ductules (Fig. 1c). Moreover, there were a large number of regenerative hepatocytes with hyperchromatic nuclei (Fig. 1c).

\section{TCE induces nuclear alterations and hepatocellular apoptosis}

Cell death, which could be induced in hepatic tissues by early exposure to TCE, was evaluated. The results showed that there was an increased hepatocyte cell death after TCE induced hepatic injury. Cell death analysis demonstrated that a large majority of hepatocytes undergone apoptosis in response to TCE treatment. Hepatocytes in TCE-treated mice displayed distinct morphological alterations in their nuclei, compared to control, represented by a prominent chromatin condensation and vacuole formation (Fig. 2a). In most cells, nuclear changes were accompanied by other degenerative changes. Most of the hepatocytes with cytoplasmic and/or nuclear degenerative changes maintained an intact plasma membrane. Limiting the counting of total hepatocyte nuclei to areas with true cross sections of hepatocytes made it possible to selectively count only the nuclei which were clearly were within a hepatocyte. The quantitative analysis of cell death revealed that the TCE-treated mice had a significant increase in the number of apoptotic hepatocytes compared to control (Fig. 2b). The vehicle control group had only rare apoptotic cells, and there was no significant difference between sham and vehicle groups. Moreover, there was no significant difference in the percentage of apoptotic hepatocytes between $100 \mu \mathrm{g} / \mathrm{kg}$ and $400 \mu \mathrm{g} / \mathrm{kg}$ TCE-treated groups (Fig. 2b). To substantiate our histological evidence for liver abnormality, a biomarker of hepatocyte count (DNA concentration and content) was used. Internucleosomal DNA fragmentation by endonuclease cleavage is a well-defined biochemical marker of cells undergoing apoptosis which results in DNA fragments, as compared to necrosis that causes nonspecific degradation of DNA into random-sized fragments (Wyllie, 1981). Nuclear DNA from control and TCE-treated mice was analyzed by agarose gel electrophoresis. DNA fragmentation was markedly induced in the TCE-treated groups when compared to that in control (Fig. 3a). A smear pattern resulting from random DNA degradation suggested

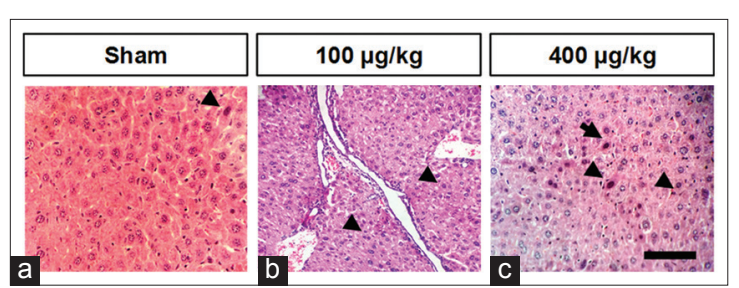

Fig. 1. Representative light photomicrograph of hepatic tissue sections from control and TCE-treated mice (H\&E 100X). (a) Hepatic tissues of sham control mice with normal hepatic lobules and hepatocytes. (b) Hepatic tissues of $100 \mu \mathrm{g} / \mathrm{kg}$ TCEtreated mice with mild steatosis and inflammatory infiltrates. (c) Hepatic tissues of $400 \mu \mathrm{g} / \mathrm{kg}$ TCE-treated mice with severe steatosis and inflammatory infiltrates. Fibrotic and hepatocyte alterations can be seen in the TCE-treated tissues. The arrows in panel $\mathrm{a}, \mathrm{b}$, and $\mathrm{c}$ indicate a cell with vacuolated and palestaining cytoplasm and alterations in nuclear morphology respectively. $\mathrm{n}=6$. Scale bar $=250 \mu \mathrm{m}$.

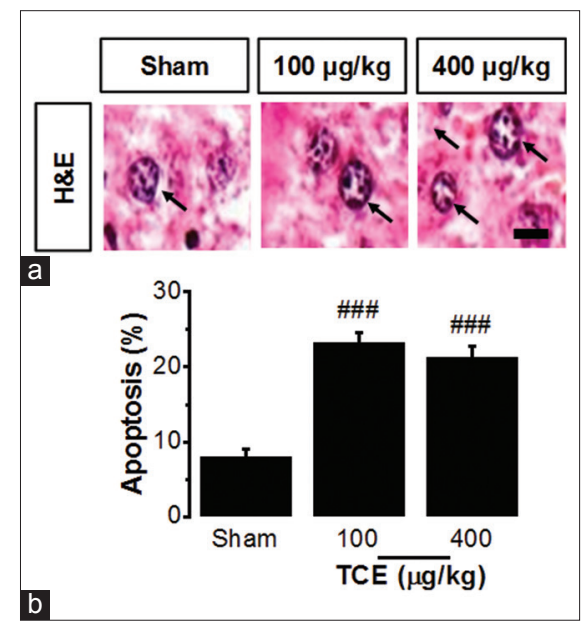

Fig. 2. Quantification of hepatocytes with fragmented DNA. (a) Representative photomicrographs of hepatic tissues from control and TCE-treated mice (H\&E 400X). Control mice nucleus showed no or little histopathological changes (normal nuclear appearance). Hepatocytes were partly lost and some cells exhibited necrotic characteristics after TCE exposure (arrows). In TCE-treated mice, the nuclei also exhibited typical apoptotic morphology as condensed and fragmented (arrows). Scale bar $=30 \mu \mathrm{m}$. (b) Quantification of hepatic cell death in control and TCE-treated mice. Data are expressed as the mean $\pm \operatorname{SEM}(\mathrm{n}=6)$. \#Significantly different from control $(P<0.05)$.

that necrosis might have occurred concurrently with apoptosis. Also there was a reduction in the DNA concentration of the TCE-treated mice (Fig. 3b). These data are consistent with the increase in the hepatocellular apoptosis. In addition, the vehicle had no significant effect on the DNA concentration when applied under normoxic conditions (Fig. 3c).

TCE increases lipid peroxidation in the hepatic tissues TCE has been shown to generate free radicals and induce oxidative stress both in vivo and in vitro (Wang 
et al., 2013). To further evaluate the role of lipid peroxidation/oxidative stress in induction of TCE mediated hepatotoxicity, formation of MDA in the liver homogenates of control and TCE-treated mice was quantified. MDA is a marker of oxidative lipid damage and a major oxidative product of peroxidized polyunsaturated fatty acids (Zhang et al., 2004). The present results showed that MDA levels in the liver homogenates were higher in both $100 \mu \mathrm{g} / \mathrm{kg}$ bw and $400 \mu \mathrm{g} / \mathrm{kg}$ bw TCE-treated groups compared to that in control (Fig. 4a), suggesting an overall increase in oxidative stress. Moreover, vehicle had no significant effect on the MDA level when applied under normoxic conditions (Fig. 4b).

\section{Discussion}

The exposure to environmental toxic chemicals can cause several detrimental effects in biological cell systems (Topham, 1980; House et al., 1996; Snyder and Andrews, 1996; Griffin et al., 2000; Wang et al., 2007, 2013; Al-Griw et al., 2015a,b,c). TCE, a widely used industrial agent and a ubiquitous environmental contaminant, is non-carcinogenic (group 3) because there is inadequate evidence for carcinogenicity in both human and animals according to EPA and National Toxicology Program (NTP) technical report (NTP, 2000; EPA, 2007). In addition, according to WHO toxicological report, TCE is not considered as toxic, and not necessary to drive a health risk based on the guideline standards (WHO, 2003). However, the Agency for Toxic Substances and Disease Registry (ATSDR) indicated that TCE affects many internal organs and systems such as cardiovascular and nervous system (Lawrence, 2006). TCE has been implicated in the development of autoimmune disorders in humans (Cooper et al., 2009) and induces autoimmune response in experimental animals (Wang et al., 2007, 2013; Cooper et al., 2009). However, the mechanisms by which TCE induces/accelerates the autoimmune disease pathogenesis are still unclear.

The present study showed that oxidative stress and apoptosis, a form of genetically programmed cell death, as a potential mechanism mediating hepatocyte cell death after exposure to low dose of TCE. A combination of techniques has been used to obtain morphological and biochemical evidence for oxidative stress and apoptosis, including biochemical markers, histopathological examination with diverse staining techniques and DNA gel electrophoresis. Although other forms of cell death might have occurred, our data suggest that both oxidative stress and apoptosis contributed to the loss of hepatocytes after TCE induced liver injury. In vivo experimental studies are crucial to evaluate environmental chemicals with adverse risk to health at birth or later in life. The in vivo study of the toxicity of chemicals is of great importance because animal systems are extremely complicated, and the interaction

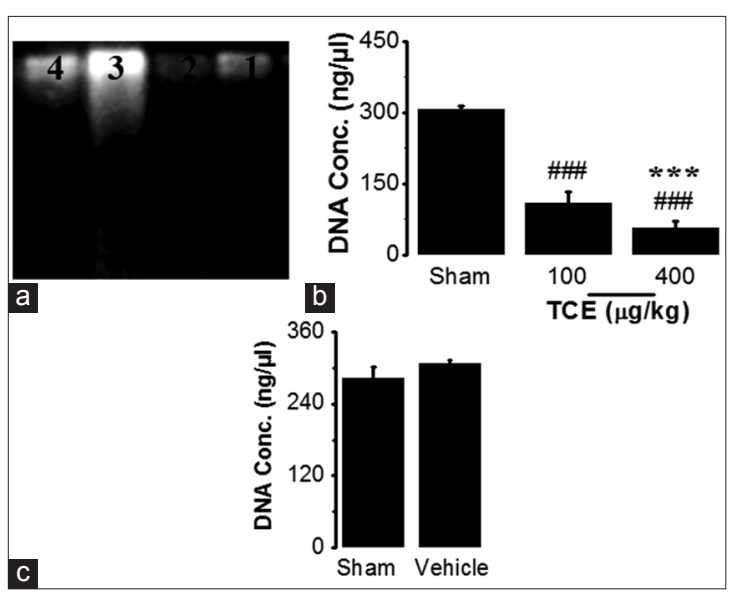

Fig. 3. DNA biomarker for hepatocytes (DNA content, quality and integrity) in control and TCE-treated mice. (a) Agarose gel electrophoresis of DNA isolated from liver of control and TCE-treated mice; sham control (lane1), vehicle control (lane2), $100 \mu \mathrm{g} / \mathrm{kg}$ TCE-treated mice (lane3) and $400 \mu \mathrm{g} / \mathrm{kg}$ TCE-treated mice (lane4). Almost no or little DNA degradation was detected in controls. DNA ladder with internucleosomal DNA fragmentation fragments appeared with a smear pattern in TCE treatment groups. (b) Quantification of DNA concentration in control and TCEtreated groups. Data are presented as the mean \pm SEM. (c) Quantification of DNA concentration in sham and vehicle groups. Data are presented as the mean $\pm \operatorname{SEM}(\mathrm{n}=6)$. *Significantly different from sham control $(P \leq 0.05)$. \#Significantly different from $100 \mu \mathrm{g} / \mathrm{kg}$ TCE-treated group $(P \leq 0.05)$.

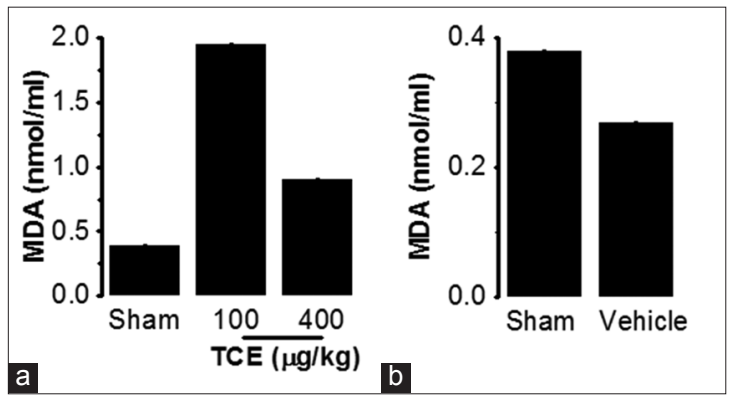

Fig. 4. Levels of oxidative stress biomarker MDA (nmol/ml) in the murine livers. (a) Quantification of levels of MDA $(\mathrm{nmol} / \mathrm{ml})$ in the livers of control and TCE-treated groups. (b) Quantification of levels of MDA $(\mathrm{nmol} / \mathrm{ml})$ in the livers of sham and vehicle groups. The values are presented as means $\pm \operatorname{SEM}(\mathrm{n}=6)$.

of chemical compounds with biological components could lead to unique biodistribution, clearance, immune responses and metabolism. The results of this study revealed that TCE insult could increase the liver weight and cause its injury. The observation detected by H\&E staining showed that the control livers presented normal features with normal hepatic lobule and normal hepatocytes, while in the TCE-treated groups, hepatocyte damage was manifested by severe steatosis 
and inflammatory infiltrates. When compared to control group, liver sections of TCE treated groups showed widely distributed pyknotic nuclei and morphological alterations in their nuclei. When referring to the TCE toxicity, prior studies (Quast et al., 1984, 1988) reported that TCE exposure have no impact on weights of body and livers in rats but can induce liver damage and affect hepatocyte counts. In contrast, we detected dominant changes in the liver, but not body, weights. The increase in the liver weight may be attributable to the inflammatory events generated due to TCE exposure as appeared in the histopathological sections of liver.

Classically, hepatocyte cell death during liver injury was indicated by either programmed (apoptosis), or accidental, uncontrolled cell death (necrosis). Growing evidence from our current understanding of the biochemical and molecular mechanisms involved in cell demise has provided an expanding view of various modes of cell death that can be triggered during both acute and chronic liver damage such as necroptosis, pyroptosis, and autophagic cell death. The complexity of noninvasively assessing the predominant mode of cell death during a specific liver insult in either experimental in vivo models or in humans is highlighted by the fact that in many instances there is significant crosstalk and overlap between the different cell death pathways (Eguchi et al., 2014).

Several studies reported evidence for apoptotic cell death during liver injury. In this study, a combination of techniques has been used to obtain morphological and biochemical evidence for apoptosis, including histopathological examination with diverse staining techniques. Light microscopy showed alterations in the nuclear morphology of hepatocytes in TCEtreated groups, which were characterized by prominent chromatin condensation and vacuole formation. Hence, we demonstrated nuclear morphological alterations in TCE hepatocytes, but not in the control groups. In most cells, nuclear changes were accompanied by other degenerative changes. Most of the hepatocytes with cytoplasmic and/or nuclear degenerative changes maintained an intact plasma membrane. Our study demonstrated that apoptosis, a form of genetically programmed cell death, is a potential mechanism mediating hepatocyte death. Although other forms of cell death might have occurred, our data suggest that apoptosis might contribute to the loss of hepatocytes in response to TCE exposure. However, the results of this study strongly suggested that the main mode of cell death after injury was necrosis, although we cannot exclude potential switch in the mode of cell death from necrosis to apoptosis.

In recent years, free radical-mediated reactions as the potential mechanism in the pathogenesis of autoimmune diseases have drawn increasing attention (Khan et al., 2001). TCE is known to generate free radicals, and cause increased lipid peroxidation in both in vivo and in vitro models (Khan et al., 2001; Wang et al., 2007). Several lines of evidence in lupus-prone mice showed that increased generation of ROS was correlated with increased autoantibodies production, illustrating a potential role of oxidative stress in TCE induced autoimmune response (Wang et al., 2007, 2010). Although there is a large body of literature addressing immune responses during environmental chemicals exposure, the TCE immunotoxicity is poorly understood. Even though TCE is known to generate free radicals, causes increased oxidative stress and induces autoimmune response (Wang et al., 2007, 2013), potential mechanisms by which TCE induced ROS generation lead to an autoimmune response and their contribution to disease pathogenesis remains largely unknown.

To further support these findings and offer new mechanistic evidence for the role of oxidative stress in TCE-induced injury, we first examined the markers of oxidative stress in TCE-treated mice. TCE- treated groups showed a significant increase in the liver MDA level in comparison to untreated groups. TCE insult also led to increased formation of MDA in sera, spleens and kidneys, major organs where TCE is known to generate free radicals and induce autoimmune disorders (Griffin et al., 2000; Wang et al., 2013), further confirming earlier findings of the potential of TCE in inducing increased lipid peroxidation. It was found that the TCE treatment can result in hepatotoxicity by elevating the oxidative stress markers MDA, hydroxynonenal (HNE)-protein, and protein oxidation (carbonylation) (Wang et al., 2013). Consistent with these findings, our results also unravel the same changes. The increase in the oxidative stress markers in the liver is attributed to the damage of hepatocytes, which is supported by the histopathological picture of the hepatic tissues.

In conclusion, our findings demonstrated that early exposure to TCE could cause serious hepatotoxicity, oxidative stress, lipid peroxidation and degeneration/ apoptosis of hepatocytes in mouse at later in life. Histopathological examination of liver tissues exposed to TCE showed heavily congested central vein and blood sinusoids, widespread pyknotic nuclei in the hepatic tissue, and leukocyte infiltration. The results also showed that TCE exposure leads to a significant induction of MDA and increases protein oxidation (carbonylation) in the liver, suggesting the potential of TCE to induce an overall increase in oxidative stress. Taken together, the results of this study suggest that oxidative stress and apoptosis might play a crucial role in hepatotoxicity of TCE. These results also provide important insights into mechanisms of TCEelicited toxicity and call for further research regarding protective measures against TCE-induced hepatocyte damage. 


\section{Acknowledgments}

This work was supported in part by the Division of Developmental Biology, Zoology Department, Faculty of Science, University of Tripoli, Tripoli, Libya.

\section{Conflict of Interest}

The authors declare that they have no competing interests.

\section{References}

Al-Griw, M.A., Salama, N.M., Treesh, S.A., Algadi, L.N. and Elnfati, A.H. 2015a. Cell Death in Mouse Brain following Early Exposure to Trichloroethane (TCE). Int. J. Adv. Res. 3(6), 1424-1430.

Al-Griw, M.A., Elnfati, A.H., Salama, N.M., Maamar, M.S., Treesh, S.A. and Shaibi, T. 2015 b. Mode of Cell Death in Mouse Brain Following Early Exposure to Low-Dose Trichloroethane: Apoptosis or Necrosis. Am. J. Biol. Life Sci. 3(6), 232-240.

Al-Griw, M.A., Salama, N.M., Treesh, S.A. and Elnfati, A.H. 2015c. Transgenerational Genetic Effect of Trichloroethane (TCE) on Phenotypic Variation of Acrosomal Proteolytic Enzyme and Male Infertility Risk. Int. J. Genet. Genomics 3(5), 43-49.

ATSDR. 2006. Toxicological Profile for 1,1,1-trichloroethane (update). U.S. Department of Health and Human Services, Public Health Service. Agency for Toxic Substances and Disease Registry. https://www.atsdr.cdc.gov/toxprofiles/tp70.pdf.

Bancroft, J.D. and Cook, H.C. 1984. Manual of Histological Techniques. Churchill Livingstone, Edinburgh, London, Melbourne, New York.

Ben Mansour, R., Lassoued, S., Elgaied,A., Haddouk, S., Marzouk, S., Bahloul, Z., Masmoudi, H., Attia, H., Aïfa, M.S. and Fakhfakh, F. 2010. Enhanced reactivity to malondialdehyde modified proteins by systemic lupus erythematosus autoantibodies. Scand. J. Rheumatol. 39, 247-253.

Chattopadhyay, P., Sharma, A.K. and Wahi, A.K. 2007. Folic acid protects hepatobiliary function in ischemic reperfusion of rat liver. Indian $\mathrm{J}$. Gastroentrol. 26, 95-96.

Chattopadhyay, P. and Wahi, A.K. 2009. Hepatocyte Deaths Occur by Apoptosis After IschemiaReperfusion Injury in the Rat Liver Transplantation Model. Trends Biomater. Artif. Organs 23, 1-5.

Cooper, G.S., Makris, S.L., Nietert, P.J. and Jinot, J. 2009. Evidence of autoimmune-related effects of trichloroethylene exposure from studies in mice and humans. Environ. Health Perspect. 117, 696-702.

Dalle-Donne, I., Rossi, R., Colombo, R., Giustarini, D. and Milzani, A. 2006. Biomarkers of oxidative damage in human disease. Clin. Chem. 52, 601-623.

Eguchi, A., Wree, A. and Feldstein, A.E. 2014.
Biomarkers of liver cell death. J. Hepatol. 60, 1063-1074.

EPA. 2007. Toxicological Review of 1,1,1-Trichloroethane (CAS No. 71-55-6). In Support of Summary Information on the Integrated Risk Information System (IRIS). EPA/635/R-03/013. U.S. Environmental Protection Agency, Washington, DC. https://cfpub.epa. gov/ncea/iris/iris documents/documents/ toxreviews/0197tr.pdf.

Griffin, J.M., Blossom, S.J., Jackson, S.K., Gilbert, K.M. and Pumford, N.R. 2000. Trichloroethylene accelerates an autoimmune response by Th1 T cell activation in MRL+/+ mice. Immunopharmacology. 46, $123-137$.

Gujral, J.S., Bucci, T.J., Farhood, A. and Jaeschke, H. 2001. Mechanism of Cell Death During Warm Hepatic Ischemia-Reperfusion in Rats: Apoptosis or Necrosis? Hepatology. 33, 397-405.

Gujral, J.S., Knight, T.R., Farhood, A., Bajt, M.L. and Jaeschke, H. 2002. Mode of cell death after acetaminophen overdose in mice: Apoptosis or oncotic necrosis? Toxicol. Sci. 67, 322-328.

House, R.A., Liss, G.M., Wills, M.C. and Holness, D.L. 1996. Paresthesias and sensory neuropathy due to 1,1,1-trichloroethane. J. occup. environ. Med. 38, 123-124.

Khan, M.F., Wu, X. and Ansari, G.A. 2001. Antimalondialdehyde antibodies inMRL $+/+$ mice treatedwith trichloroethene and dichloroacetyl chloride: Possible role of lipid peroxidation in autoimmunity. Toxicol. Appl. Pharmacol. 170, 88-92.

Kurose, I., Higuchi, H., Miura, S., Saito, H., Watanabe, N., Hokari, R., Hirokawa, M., Takaishi, M., Zeki, S., Nakamura, T., Ebinuma, H., Kato, S. and Ishii, H. 1997. Oxidative stressmediated apoptosis of hepatocytes exposed to acute ethanol intoxication. Hepatology. 25, 368-378.

Lane, R.W., Riddle, B.L. and Borzelleca, J.F. 1982. Effects of 1,2-dichloroethane and 1,1,1-trichloroethane in drinking water on reproduction and development in mice. Toxicol. Appl. Pharmacol. 63, 409-421.

Lawrence, S.J. 2006. Description, properties, and degradation of selected volatile organic compounds detected in ground water-A Review of Selected Literature: Atlanta, Georgia, U. S. Geological Survey, Open-File Report 2006-1338, 62 pages, a Web-only publication at: http://pubs.usgs.gov/ ofr/2006/1338/.

Mackay, C.J., Campbell, L., Samuel, A.M., Alderman, K.J., Idzikowski, C., Wilson, H.K. and Gompertz, D. 1987. Behavioral changes during exposure to 1,1,1-trichloroethane: Time-course and relationship to blood solvent levels. Am. J. Ind. 
Med. 11, 223-239.

Melani, A., Pantoni, L. and Bordoni, F. 2003. The selective A2A receptor antagonist $\mathrm{SCH} 58261$ reduces striatal transmitter outflow, turning behavior and ischemic brain damage induced by permanent focal ischemia in the rat. Brain Res. 959, 243-250.

Morgan, P.E., Sturgess, A.D. and Davies, M.J. 2005. Increased levels of serum protein oxidation and correlation with disease activity in systemic lupus erythematosus. Arthritis Rheum. 52, 2069-2079.

NTP. 2000. NTP technical report on the toxicity studies of 1,1,1-trichloroethane administered in microcapsules in feed to $\mathrm{F} 344 / \mathrm{N}$ rats and $\mathrm{B} 6 \mathrm{C} 3 \mathrm{~F} 1$ mice. National Toxicology Program. (41) NIH 004402. Www.michigan.gov/./deq-rrd-chem-111TrichloroethaneDatasheet_527455_7.pdf.

Oates, J.C. 2010. The biology of reactive intermediates in systemic lupus erythematosus. Autoimmunity 43, 56-63.

Orengo, C.A., Todd, A.E. and Thornton, J.M. 1999. From protein structure to function. Curr. Opin. Struct. Biol. 9, 374-382.

Quast, J.F., Calhoun, L.L. and Frauson, L.E. 1988. 1,1,1-trichloroethane formulation: A chronic inhalation toxicity and oncogenicity study in Fischer 344 rats and B6c3F1 mice. Fundam. Appl. Toxicol. 11, 611-625.

Quast, J.F., Calhoun, L.L. and McKenna, M.J. 1984. Chlorothene VG: A chronic inhalation toxicity and oncogenicity study in rats and mice (part 1 and 2) with cover letter dated 08/21/1984. The Dow Chemical Company, Midland, MI. Submitted under TSCA Section 4; EPA Document No. 40-8424496; NTIS No. OTS0510656. https://cfpub.epa.gov/ ncea/iris/iris_documents/documents/subst/0197 summary.pdf.

Snyder, R. and Andrews, L.S. 1996. Toxic effects of solvents and vapors. In: Klaassen, CD; ed. Casarett and Doull's Toxicology: The Basis Science of Poisons, $5^{\text {th }}$ ed. New York: McGraw-Hill, pp: 133-186.

Topham, J.C. 1980. Do induced sperm-head abnormalities in mice specifically identify mammalian mutagens rather than carcinogens? Mutat. Res. 74, 379-387.

Utley, H.G., Bernheim, F. and Hochstein, P. 1967. Effect of sulfhydryl reagents on peroxidation in microsomes. Arch. Biochem. Biophys. 118, 29-32.

Wang, G., Cai, P., Ansari, G.A.S. and Khan, M.F. 2007. Oxidative and nitrosative stress in trichloroethenemediated autoimmune response. Toxicology 229, 186-193.

Wang, G., Pierangeli, S.S., Papalardo, E., Ansari, G.A. and Khan, M.F. 2010. Markers of oxidative and nitrosative stress in systemic lupus erythematosus: Correlation with disease activity. Arthritis Rheum. 62, 2064-2072.

Wang, G., Wang, J., Ma, H., Ansari, G.A.S. and Khan, M.F. 2013. N-Acetylcysteine protects against trichloroethene-mediated autoimmunity by attenuating oxidative stress. Toxicol. Appl. Pharmacol. 273, 189-195.

Wang, W., Hafner, K.S. and Flaws, J.A. 2014. In utero bisphenol A exposure disrupts germ cell nest breakdown and reduces fertility with age in the mouse. Toxicol. Appl. Pharmacol. 276, 157-164.

Warren, D.A., Reigle, T.G., Muralidhara, S. and Dallas, C. 1998. Schedule-controlled operant behavior of rats during 1,1,1-trichloroethane inhalation: Relationship to blood and brain solvent concentrations. Neurotoxicol. Teratol. 20, 143-153.

WHO. 2003. 1,1,1-Trichloroethane in Drinking-water. Background document for development of WHO Guidelines for Drinking-water Quality. World Health Organization WHO/SDE/WSH/03.04/65., 16. www.who.int/water_sanitation_health/dwq/ chemicals/111-Trichloroethane.pdf

Wyllie, A. 1981. Cell death: A new classification separating apoptosis from necrosis. In: Bowen ID LR, ed. Cell death in biology and pathology. Chapman and Hall: London, England, pp: 9-34.

Zhang, Y.T., Zheng, Q.S., Pan, J. and Zheng, R.L. 2004. Oxidative damage of biomolecules in mouse liver induced by morphine and protected by antioxidants. Basic Clin. Pharmacol. Toxicol. 95, 53-58. 